\title{
Avaliação da atividade antiedematogênica, antimicrobiana e mutagênica das sementes de Amburana cearensis (A. C. Smith) (Imburana-de-cheiro)
}

LIMA, L.R.'; CAVALCANTE, R.R.L.'; MARTINS, M.C.C.'; PARENTE, D.M.1,3; CAVALCANTE, A.A.M.C. ${ }^{1,4}$ ${ }^{1}$ Faculdade de Saúde, Ciências Humanas e Tecnológicas do Piauí (NOVAFAPI), Rua Vitorino Orthiges Fernandes, 6123 - Bairro Uruguai | CEP: 64073-505, Teresina - Piauí. laisr_@hotmail.com*; rossanarlc@hotmail.com*; 2Departamento de Biofísica e Fisiologia(UFPl). mcmartins@novafapi.com.br; ${ }^{2}$ daniela_parente@hotmail.com; ${ }^{4}$ Depto Ciências Farmacêuticas (UFPI). ana_ameliamelo@ibest.com.br.

RESUMO: Foram avaliados os efeitos antiinflamatório, antibacteriano e mutagênico do extrato aquoso das sementes de Amburana cearensis. A atividade antiinflamatória foi avaliada em modelo de edema de pata induzido por carragenina, utilizando o extrato em concentrações de $10 \%$ e $20 \%$ nos grupos experimentais; AAS $10 \mathrm{mg} / \mathrm{kg}$ (v.o) no grupo padrão e água destilada no grupo controle. A atividade antimicrobiana foi determinada através do método de diluição em Agar, utilizando concentrações de extrato de $10 \%, 7,5 \%, 5 \%, 2,5 \%$ e 1 \% em cepas de Sthaphylococcus aureus ATCC 27853, Escherichia coli ATCC 25922 e Pseudomonas aeruginosas ATCC 25923) e a atividade mutagênica foi determinada pelo teste de Allium cepa, utilizando extrato em concentrações de $0,02 \mathrm{mg} / \mathrm{mL}, 0,1 \mathrm{mg} / \mathrm{mL}$ e 0,5 $\mathrm{mg} / \mathrm{mL}$. O extrato aquoso das sementes de Amburana cearensis nas concentrações de $10 \%$ e $20 \%$ apresentou efeito antiedematogênico, estatisticamente significativo a partir de duas horas após administração do flogógeno, e tal efeito persistiu até 24 horas após a indução da resposta inflamatória. Quanto à atividade antibacteriana, o extrato não apresentou ação contra as cepas bacterianas de Sthaphylococcus aureus, Escherichia coli e Pseudomonas aeruginosas nas concentrações testadas. A análise dos resultados do teste de Allium cepa evidenciou ação tóxica (em concentração de $0,5 \mathrm{mg} / \mathrm{mL}$ ) e mutagênica (micronúcleo $0,1 \mathrm{mg} / \mathrm{mL}$ e aberrações cromossômicas $0,1 \mathrm{mg} / \mathrm{mL}$ e $0,5 \mathrm{mg} / \mathrm{mL}$ ) do extrato de Amburana cearensis em células meristemáticas de Allium cepa. Tais resultados sugerem potencial aplicação terapêutica no tratamento da inflamação. Contudo, também demonstram a necessidade de estudar para comprovar a segurança na utilização dessa espécie.

Palavras chaves: Amburana cearensis. Planta medicinal. Edema. Antimicrobiano. Mutagênico.

ABSTRACT: Assessment of the antiedematogenic, antimicrobial and mutagenic activity of Amburana cearensis seeds (A.C. Smith) (Imburana-de-cheiro). The anti-inflammatory, antibacterial and mutagenic effects of the aqueous extract of Amburana cearensis seeds were evaluated. The anti-inflammatory activity was evaluated by a paw edema model induced by carrageenan, using the extract at $10 \%$ and $20 \%$ concentrations in the experimental groups: AAS $10 \mathrm{mg} / \mathrm{kg}$ (orally administrated) in the standard group and distilled water in the control group. The antimicrobial activity was determined by the agar dilution method, using extract concentrations of $10 \%, 7.5 \%, 5 \%, 2.5 \%$ and $1 \%$ in strains of Staphylococcus aureus ATCC 27853, Escherichia coli ATCC 25922 and Pseudomonas aeruginosas ATCC 25923), and the mutagenic activity was determined by the Allium cepa test using extract concentrations of 0,02 $\mathrm{mg} / \mathrm{mL}, 0,1 \mathrm{mg} / \mathrm{mL}$ and $0,5 \mathrm{mg} / \mathrm{mL}$. The aqueous extract of Amburana cearensis seeds at 10 $\%$ and $20 \%$ concentrations had an statistically significant antiedematogenic effect two hours after administering the flogogen, and this effect persisted for up to 24 hours after inducing the inflammatory response. Regarding the antibacterial activity, the extract showed no action against the bacterial strains of Staphylococcus aureus, Escherichia coli and Pseudomonas aeruginosas at the concentrations tested. The results of the Allium cepa test showed the toxic (at a concentration of $0,5 \mathrm{mg} / \mathrm{mL}$ ) and mutagenicity $(0.1 \mathrm{mg} / \mathrm{mL}$ micronucleus and $0.1 \mathrm{mg} /$ $\mathrm{mL}$ and $0.5 \mathrm{mg} / \mathrm{mL}$ chromosomal aberrations) actions of the Amburana cearensis extract on meristematic cells of Allium cepa. These results suggest potential therapeutic applications to treat inflammations. However, they also show the need for further studies to demonstrate the safe use of this species.

Keywords: Amburana cearensis. Medicinal Plant. Edema. Antimicrobial. Mutagenic.

Recebido para publicação em 10/12/2011

Aceito para publicação em 22/01/2013

Rev. Bras. PI. Med., Campinas, v.15, n.3, p.415-422, 2013. 


\section{INTRODUÇÃO}

As plantas medicinais representam opção terapêutica de grande importância para a manutenção das condições de saúde das pessoas, especialmente para a população de baixa renda. A diferença entre planta medicinal e produto fitoterápico reside no fato de que para ser considerado fitoterápico deve ser elaborada uma formulação específica da planta medicinal (RDC N ${ }^{\circ} 48$ de 16-03-04 - ANVISA). Além da comprovação da ação terapêutica de várias plantas utilizadas popularmente, a fitoterapia representa parte importante da cultura de um povo, sendo também parte de um saber utilizado e difundido pelas populações ao longo de várias gerações. A observação do comportamento dos animais e a verificação empírica dos efeitos da ingestão de vegetais no organismo humano tiveram um importante papel: a descoberta da cura de enfermidades através de plantas medicinais. Essa prática popular vem contribuindo para pesquisas científicas e divulgação de propriedades terapêuticas validando ou não o uso de determinadas plantas medicinais (Tomazzoni et al., 2006).

Numerosas plantas são utilizadas com fins terapêuticos pela população brasileira, contudo poucas têm ação comprovada, o que desperta o interesse de pesquisadores em estudos envolvendo áreas multidisciplinares como, botânica, química, farmacologia, microbiologia e toxicologia, que juntas enriquecem os conhecimentos sobre a inesgotável fonte medicinal natural: a flora mundial (Maciel et al., 2002).

De acordo com Bagatini et al. (2007), mundialmente muitas espécies de plantas medicinais são utilizadas para o tratamento de doenças. No entanto, a maioria dessas espécies não foram suficientemente estudadas, principalmente quanto à presença de substâncias citotóxico-mutagênicas em sua composição ou decorrentes do próprio metabolismo, e que podem causar danos à saúde da população. A presença de substâncias mutagênicas nas espécies vegetais que causam alterações cromossômicas pode ser detectada durante o ciclo celular de uma espécie (Peron et al., 2009)

Entre as propriedades farmacológicas estudadas em produtos naturais está a ação antiinflamatória. A principal característica do processo inflamatório é a reação dos vasos sanguíneos que leva ao acúmulo de fluidos e leucócitos nos tecidos extravasculares, e essas respostas inflamatórias podem ter efeitos benéficos ou maléficos para o organismo, além de estarem intimamente ligadas ao processo de reparo.
Nesse sentido, inibir um processo inflamatório é fundamental para a não disseminação de uma doença (Brito et al., 2006).

Considerando ainda que ouso indiscriminado e prolongado de antimicrobianos determina um processo de seleção de microrganismos patogênicos mutantes, a resistência bacteriana aos antimicrobianos é considerada como um problema inerente à terapia antimicrobiana e por este motivo é preciso sempre buscar novas fontes terapêuticas. Testar produtos naturais pode ser uma medida alternativa importante para ajudar a resolver esse problema de resistência (Silva et al.; 2010).

A resposta inflamatória inclui a participação de diferentes tipos celulares, tais como neutrófilos, macrófagos, mastócitos, linfócitos, plaquetas, células dendríticas, células endoteliais e fibroblastos, entre outras. Durante a infecção, a quimiotaxia é um importante evento para o recrutamento de células para o sítio de inflamação. As primeiras células a chegar ao parênquima lesado são os neutrófilos e, subseqüentemente, os macrófagos teciduais. As respostas de defesa, incluindo inflamação, são geralmente benéficas ao organismo, agindo para limitar a sobrevivência e proliferação dos patógenos invasores, promoverem a sobrevivência do tecido, reparo e recuperação, e conservar a energia do organismo. Entretanto, uma inflamação extensa, prolongada ou não regulada, é altamente prejudicial ao organismo. Processos pró-inflamatórios são regulados por uma série equivalente de processos antiinflamatórios teciduais (Lima et al., 2007).

As sementes e casca do caule Amburana cearensis são popularmente utilizados em forma de extrato aquoso (chá) para o tratamento de gripe, resfriado, asma, cólicas, derrame, dores no corpo, dentre outras (Rossi, 2008; Canuto, 2008). De acordo com Canuto \& Silveira (2006) e Cunha \& Ferreira (2003), a Amburana cearensis (A. C. Smith), pertencente à família Fabaceae, é típica da região nordeste do Brasil, sendo popularmente conhecida como umburana, imburana-de-cheiro, cerejeira, cumaru do Ceará. Apresenta como características botânicas porte regular, flores brancas, vagem achatada, seca e escura, sementes pretas e arredondadas e a casca do caule vermelho- pardacento. As sementes e a casca do caule possuem constituintes como a cumarina, que são lactonas do ácido o-hidroxi-cinâmico, com atividade antiinflamatória, anticoagulante, vasodilatadora, espasmolítica e antitrombótica. Neste estudo foram avaliados os efeitos antiedematogênico, antibacteriano e mutagênico do extrato aquoso das sementes de Amburana cearensis. 


\section{METODOLOGIA}

\section{Tipo de pesquisa e local de estudo}

Trata-se de uma pesquisa experimental realizada no Laboratório de Cirurgias Experimentais e na Clínica de Biomedicina do Centro Integrado de Saúde da Faculdade NOVAFAPI e, situada na Rua Vitorino Orthiges Fernandes $n^{\circ}$ 6123, Bairro do Uruguai, zona leste de Teresina, no mês de Setembro de 2011.

\section{Material Vegetal}

As sementes da Amburana cearensis foram coletadas no município de Corrente, estado do Piauí, localizado na região Nordeste do Brasil. Antes da realização dos experimentos a planta foi identificada e catalogada no Herbário Graziela Barroso (Exsicata $n^{\circ}$ 27.889) em Teresina-PI, em Agosto de 2011.

\section{Obtenção do extrato aquoso das sementes de Amburana cearensis \\ O extrato aquoso para o teste farmacológico} de atividade antiedematogênica foi preparado em duas concentrações distintas, respectivamente a 10 e $20 \%$, peso/volume. Para preparar o extrato foram adicionados $100 \mathrm{~mL}$ de água destilada fervente às sementes (secas e trituradas) em recipiente, mantido fechado durante 15 minutos. Depois de frio, o extrato foi filtrado e administrado em volume correspondente a $5 \mathrm{~mL} / \mathrm{kg}$ de peso corporal do animal, conforme previsto no protocolo experimental.

$\mathrm{Na}$ avaliação microbiológica, foram preparados extratos em concentrações de $1 \%, 2,5$ $\%, 5 \%, 7,5 \%$ e $10 \%$, e para a avaliação mutagênica foram preparados extratos em concentrações de 0 , $02,0,1$ e $0,5 \mathrm{mg} / \mathrm{mL}$.

\section{Animais}

Foram utilizadas 28 fêmeas de ratos da

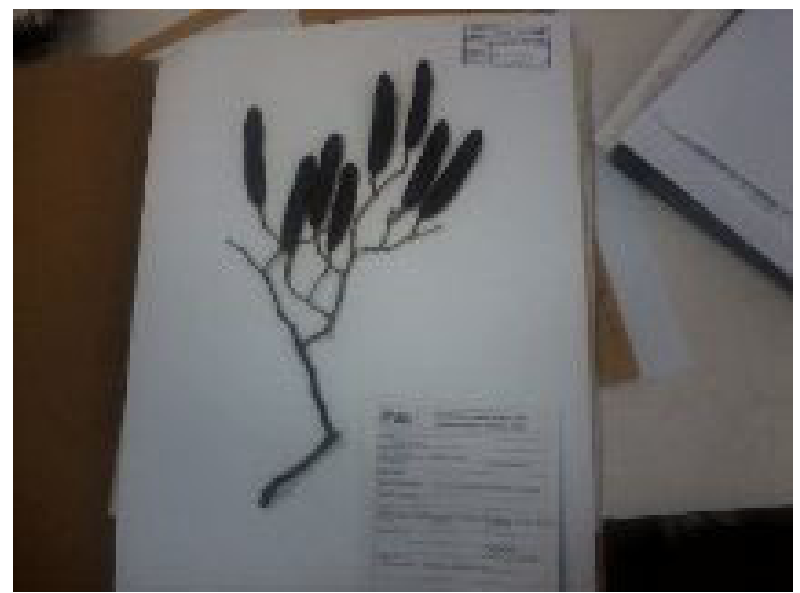

FIGURA 1: Exsicata de espécie Amburana cearensis $\left(n^{\circ} 27.889\right)$ depositada no Herbário Graziela Barroso - UFPI. espécie Rattus norvegicus, com peso corporal entre $166 \mathrm{~g}$ a $254 \mathrm{~g}$, com idade entre 13 e 16 semanas. Os animais foram mantidos em sala com temperatura de $25-26{ }^{\circ} \mathrm{C}$, acomodados em gaiolas coletivas (5 animais/gaiolas), com ração padrão para ratos e água ad libitum e ciclo de claro-escuro de $12 \mathrm{~h}$.

\section{Estudo de atividade antiinflamatória em modelo de edema de pata induzido por carragenina}

Os animais foram distribuídos aleatoriamente em quatro grupos de sete ratos. Trinta minutos antes da injeção de carragenina, os grupos experimentais receberam o extrato aquoso das sementes da Amburana cearensis por via oral (v.o.), nas concentrações $10 \%$ e $20 \%$, correspondente a $500 \mathrm{mg} / \mathrm{kg}$ (grupo EAAC500) e $1000 \mathrm{mg} / \mathrm{kg}$ (grupo EAAC1000); o grupo Controle Positivo recebeu AAS $10 \mathrm{mg} / \mathrm{kg}$ (v.o), e o grupo Controle Negativo recebeu veículo (água destilada). Transcorridos, 30 minutos da administração, o edema de pata foi induzido pela injeção de $0,1 \mathrm{~mL}$ de carragenina 1 \% em solução salina, por via subcutânea, na área plantar da pata posterior direita de cada animal. Nos animais do grupo controle foi injetado igual volume de solução salina. $O$ volume da pata foi medido por pletismografia após $1 \mathrm{~h}, 2 \mathrm{~h}, 3 \mathrm{~h}, 4 \mathrm{~h}$ e $24 \mathrm{~h}$ da administração da carragenina.

Contagem global e diferencial de leucócitos

A contagem de leucócitos foi realizada em amostra de sangue venoso obtida 24 h após administração de carragenina. Para isso, alíquota

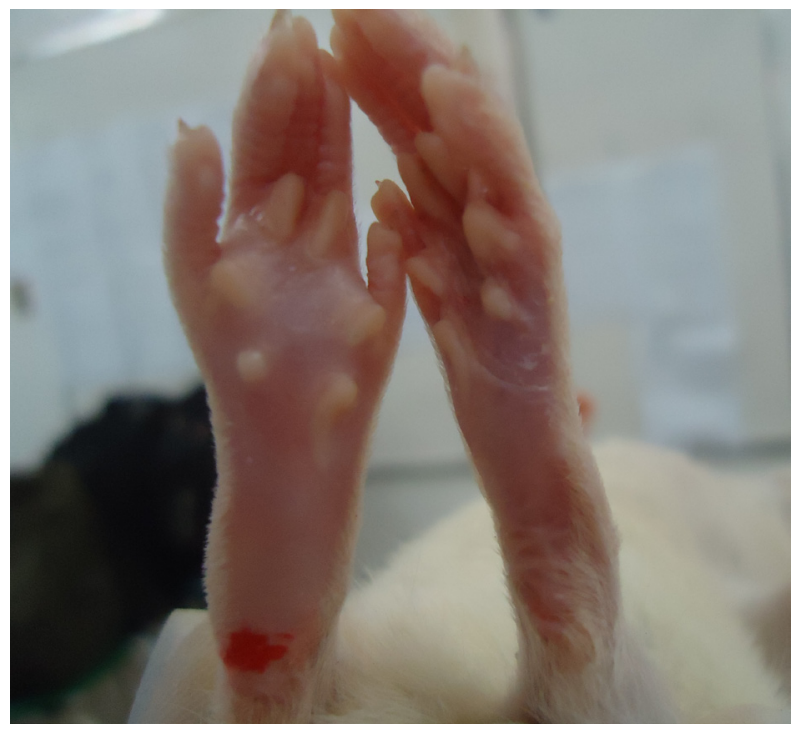

FIGURA 2: Fotografia de edema de pata induzido por carragenina a $1 \%$ trinta minutos após a administração do extrato aquoso nas concentrações de 10 e $20 \%$ na pata posterior direita do animal via subcutânea ou veículo (água destilada). Na pata posterior esquerda foi administrado igual volume do veículo. 
de $20 \mu \mathrm{L}$ de sangue total foi diluída em $0,4 \mathrm{~mL}$ de solução de Turk. Realizou-se a contagem global de leucócitos em câmara de Neubauer. Posteriormente, foi realizado o esfregaço sanguíneo em lâminas com uma gota de sangue total e corado com Panótipo, que foi analisado por microscopia óptica com aumento de $100 \mathrm{x}$.

\section{Eutanásia}

Os animais utilizados no estudo de atividade antiedematogênica, após 24 horas de administração de carragenina receberam sobredose de tiopental sódico $100 \mathrm{mg} / \mathrm{kg}$, por via intraperitoneal, para eutanásia (Massone, 2002).

\section{Avaliação de atividade antimicrobiana pelo método de diluição em Agar \\ A atividade antimicrobiana do extrato} aquoso de Amburana cearensis foi testada em concentrações de $1 \%, 2,5 \%, 5 \%, 7,5 \%$ e $10 \%$ em meio Agar, preparado por diluição de $3,8 \mathrm{~g}$ de Agar Mueller Hinton em $100 \mathrm{~mL}$ de água destilada. O meio de cultura foi distribuído nas placas para testar efeito das diferentes concentrações do extrato. As placas de cultura foram semeadas com cepas padrão de Sthapylococcus aureus (ATCC 27853), Escherichia coli (ATCC 25922) e Pseudomonas aeruginosas (ATCC 25923) com o auxílio de uma alça de platina, e estocadas em estufa a $37^{\circ} \mathrm{C}$ por 48 horas.

\section{Avaliação da Atividade Mutagênica}

O teste Allium cepa foi realizado segundo protocolo de Fiskesjo (1985) modificado, submetendo-se raízes de meristemas de Allium cepa (cebola) a amostras de extrato aquoso de Amburana cearensis nas concentrações de 0,02 $\mathrm{mg} / \mathrm{mL}, 0,1 \mathrm{mg} / \mathrm{mL}$ e $0,5 \mathrm{mg} / \mathrm{mL}$, em água de poço para controle negativo e em solução de sulfato de cobre a $0,6 \mathrm{mg} / \mathrm{mL}$ para controle positivo.

\section{Análise Estatística}

Os resultados são apresentados como média e erro padrão da média para cada grupo. As comparações entre os grupos foram realizadas por meio de Análise de Variância de uma via (ANOVA one way) e teste de Newman-Keuls. Para teste de Allium cepa as variáveis de mutagenicidade foram avaliadas por meio de ANOVA e teste Dunnett's para comparação de médias dos diferentes parâmetros. O nível de significância foi estabelecido em $p<0,05$. As análises foram realizadas utilizando o programa Grahpad Prism versão 5.0.

\section{Aspectos éticos}

O estudo foi aprovado previamente pelo Comitê de Ética em Pesquisa da Faculdade Novafapi, processo $N^{\circ}$ 0019/11. A pesquisa foi realizada em conformidade com os princípios éticos de experimentação animal definido pelo Conselho Nacional de Controle da Experimentação AnimalCONCEA, e todas as normas vigentes no Brasil.

\section{RESULTADOS}

$\mathrm{Na}$ avaliação do efeito antiedematogênico do extrato aquoso das sementes de Amburana cearensis no modelo de edema de pata induzido por carragenina (Tabela 1), observou-se que os grupos tratados com extrato nas duas doses utilizadas apresentaram variação do volume de pata significativamente menor $(p<0,05)$ nos tempos 2 , 3 , 4 e 24 horas quando comparados com o grupo controle. O efeito aintiedematogênico do extrato nas duas doses utilizadas foi semelhante àquele obtido no grupo tratado com AAS 2 e 3 horas após a indução do edema, e foi significativamente maior $(p<0,05)$ que a do referido grupo em 4 e 24 horas após a administração do flogógeno.

$\mathrm{Na}$ análise hematológica foi observada a

TABELA 1: Variação do volume da pata $(\mathrm{mL})$ de ratos tratados com extrato aquoso de sementes de Amburana cearensis (500 e $1000 \mathrm{mg} / \mathrm{kg}$ ), veículo padrão ácido acetilsalicílico (10 mg/kg) nos tempos de 1, 2, 3, 4 e 24 horas após administração de carragenina 1\%, veículo s.c. na área plantar da pata posterior direita.

\begin{tabular}{|c|c|c|c|c|c|c|c|c|c|}
\hline \multirow[t]{2}{*}{$\begin{array}{r}\text { Grupos/ } \\
\text { Tempo }\end{array}$} & \multirow[t]{2}{*}{$\mathbf{N}$} & \multicolumn{2}{|c|}{$\begin{array}{c}\text { Grupo Controle } \\
\text { Positivo }\end{array}$} & \multicolumn{2}{|c|}{$\begin{array}{c}\text { Grupo Controle } \\
\text { Negativo }\end{array}$} & \multicolumn{3}{|c|}{$\begin{array}{c}\text { Extrato Aquoso } \\
10 \%\end{array}$} & \multirow{2}{*}{$\begin{array}{r}\text { Extrato Aquoso } \\
20 \% \\
\text { Desvio Padrão }\end{array}$} \\
\hline & & Média & Desvio Padrão & Média & Desvio Padrão & Média & Desvio Padrão & Média & \\
\hline $1 \mathrm{~h}$ & 7 & 0,11 & 0,04 & 0,21 & 0,08 & 0,09 & 0,05 & 0,01 & 0,06 \\
\hline $2 \mathrm{~h}$ & 7 & $0,18 \mathrm{e}$ & 0,06 & 0,42 & 0,07 & $0,05^{a}$ & 0,01 & $0,08 \tilde{n}$ & 0,06 \\
\hline $3 \mathrm{~h}$ & 7 & $0,29 \mathrm{e}$ & 0,03 & 0,48 & 0,07 & $0,14^{a}$ & 0,07 & $0,12 \tilde{n}$ & 0,06 \\
\hline $4 \mathrm{~h}$ & 7 & 0,39 & 0,05 & 0,47 & 0,06 & $0,08^{a b}$ & 0,06 & $0,10 \tilde{n} d$ & 0,07 \\
\hline $24 \mathrm{~h}$ & 7 & 0,28 & 0,05 & 0,36 & 0,07 & $0,05^{a b}$ & 0,02 & $0,05 \tilde{n} \mathrm{~d}$ & 0,02 \\
\hline
\end{tabular}

Teste ANOVA/ Neuman Keuls Comaparison Teste $(p<0,05)$. a Extrato aquoso $10 \%$ versus Controle Negativo; ${ }^{b}$ Extrato aquoso $10 \%$ versus

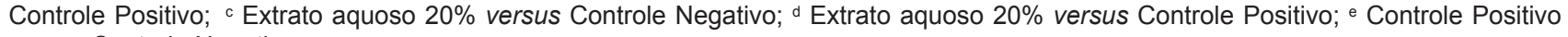
versus Controle Negativo. 
TABELA 2. Contagem global e diferencial de células sanguíneas e intervalo de confiança para as contagens de ratos tratados com extrato aquoso de sementes de Amburana cearensis (500 e $1000 \mathrm{mg} / \mathrm{kg}$ ), veículo padrão ácido acetilsalicílico (10 mg/kg) e veículo controle, 24 horas após administração de carragenina 1\%, veículo s.c. na área plantar da pata posterior direita.

\begin{tabular}{|c|c|c|c|c|}
\hline $\begin{array}{l}\text { Contagem global e diferencial de } \\
\text { células sanguíneas (\%) }\end{array}$ & $\mathbf{N}$ & Média & Desvio padrão & Intervalo de confiança $(95 \%)$ * \\
\hline Leucócitos $\left(10^{3} / \mathrm{mm}^{3}\right)$ & 7 & 4,35 & 1,36 & $3,7-5,3$ \\
\hline Neutrófilos ( \%) & 7 & 36,85 & 8,81 & $26,0-36,1$ \\
\hline Eosinófilos (\%) & 7 & 5,28 & 0,88 & $0-0,6$ \\
\hline Bastão (\%) & 7 & 6,07 & 2,54 & $0,41-2,63$ \\
\hline Linfócitos (\%) & 7 & 48 & 12,79 & $60,3-71,4$ \\
\hline Monócitos (\%) & 7 & 1,44 & 0,92 & $1,3-4,2$ \\
\hline Plaquetas $\left(10^{3} / \mathrm{mm}^{3}\right)$ & 7 & 22,8 & 0,27 & $4,6-6,8$ \\
\hline
\end{tabular}

${ }^{\star}$ Extraído de Messias, J. B. et al. Parâmetros hematológicos de Rattus norvegicus obtidos através de método automatizado e não automatizado. Medicina Veterinária, Recife, v.3, n.2, p. 1-8, Abr-Jun, 2009.

presença de agregação plaquetária em sangue coletado 24 horas após indução do edema de pata por carragenina, além de neutrófilos em forma hipersegmentada e linfócitos atípicos em todos os grupos (Tabela 2).

No estudo microbiológico realizado com extrato aquoso das sementes de Amburana cearensis preparado em cinco concentrações distintas $10 \%, 7,5 \%, 5 \%, 2,5 \%$ e $1 \%$ não foi demonstrada atividade antibacteriana, pois não houve a inibição do crescimento das cepas de Sthapylococcus aureus, Escherichia coli, Pseudomonas aeruginosas (Figura 3).

Quanto ao estudo do efeito do extrato aquoso das sementes de Amburana cearensis no sistema teste Allium cepa, observou-se que o extrato

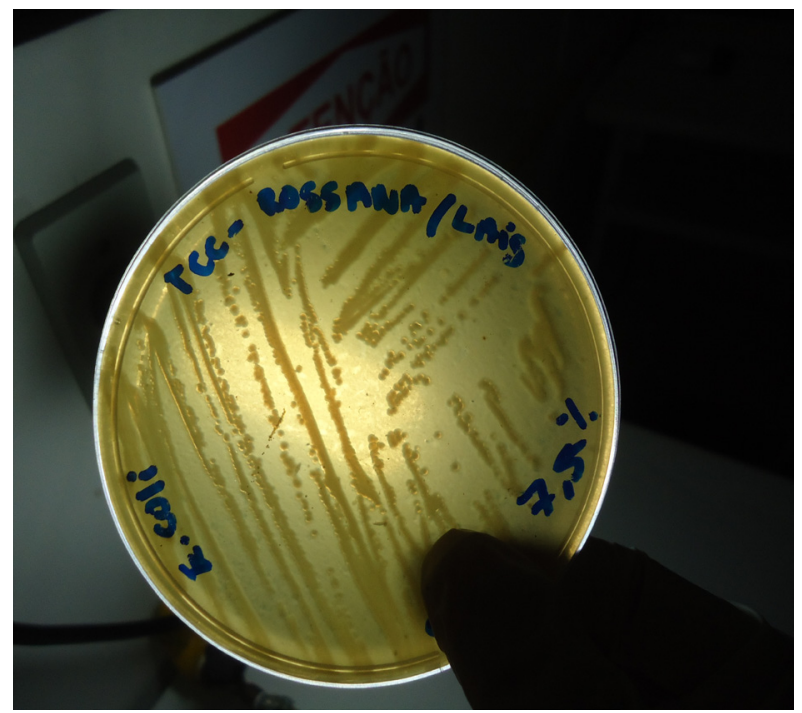

FIGURA 3. Placa semeada com cepa de Escherichia coli em meio contendo o extrato aquoso das sementes de Amburana cearensis em concentração de $7,5 \%$ peso/volume. apresentou ação tóxica evidenciada pelo crescimento de raízes acima de $2,0 \mathrm{~cm}$ de comprimento com utilização de extrato em concentração de $0,5 \mathrm{mg} / \mathrm{mL}$, bem como mostrou ação mutagênica caracterizada pelo aumento significativo da freqüência de aberrações e de micronúcleos com a utilização de extrato, nas concentrações de $0,1 \mathrm{mg} / \mathrm{mL}$ e $0,5 \mathrm{mg} /$ $\mathrm{mL}$, respectivamente, em relação ao grupo controle negativo (Tabela 3 ).

\section{DISCUSSÃO}

A fitoterapia é tema de diversos estudos em praticamente todo o mundo. A eficácia e segurança do uso, e o controle da qualidade de algumas plantas utilizadas na medicina popular foram confirmadas e outras continuam em estudo por meio de testes farmacológicos, toxicológicos e químicos (Maciel et al., 2002).

Segundo Maciel (2002) as observações populares sobre o uso e a eficácia de plantas medicinais contribuem de forma relevante para a divulgação das virtudes terapêuticas dos vegetais prescritos com freqüência pelos efeitos medicinais que produzem, apesar de não terem seus constituintes químicos conhecidos. $O$ valor das plantas medicinais, aromáticas e condimentares é determinado pelos compostos químicos especiais, elaborados por elas e que são chamados princípios ativos (Junior et al., 2006). As plantas não são unicamente uma fonte potencial de princípios ativos quimicamente definidos, uma vez que o uso de extratos delas obtidos também é possível. E, para o uso dos extratos com fins terapêuticos sua atividade farmacológica deve estar definida, assim como os compostos responsáveis por esta atividade (Foglio et al., 2006).

A atividade antiedematogênica do extrato 
TABELA 3. Índice mitótico, crescimento das raízes, micronúcleos e aberrações cromossômicas (média \pm desvio padrão) de espécimes de Allium cepa expostos às concentrações de $0,02 \mathrm{mg} / \mathrm{mL} ; 0,1 \mathrm{mg} / \mathrm{mL}$ e $0,5 \mathrm{mg} / \mathrm{mL}$ do extrato aquoso das sementes de Amburana cearensis.

\begin{tabular}{|c|c|c|c|c|}
\hline $\begin{array}{l}\text { Parâmetros } \\
\text { Analisados }\end{array}$ & $\begin{array}{l}\text { Índice Mitótico } \\
\text { (IM) \% }\end{array}$ & $\begin{array}{l}\text { Crescimento das } \\
\text { raízes em }(\mathrm{cm})\end{array}$ & $\begin{array}{l}\text { Micronúcleo (MN) } \\
\% 5.000 \text { células }\end{array}$ & $\begin{array}{l}\text { Aberrações (AC) } \\
\% 5.000 \text { células }\end{array}$ \\
\hline Controle negativo & $80,90 \pm 10,45$ & $0,35 \pm 0,07$ & $0,02 \pm 0,04$ & $0,08 \pm 0,08$ \\
\hline Controle positivo & $37,00 \pm 8,07^{* * *_{a}}$ & $2,55 \pm 1,26^{* * \star a}$ & $0,48 \pm 0,16^{* * *_{a}}$ & $0,70 \pm 0,75$ \\
\hline Extrato aquoso $0,02 \mathrm{mg} / \mathrm{mL}$ & $87,22 \pm 24,89$ & $1,95 \pm 0,08$ & $0,0 \pm 0,0$ & $0,22 \pm 0,14$ \\
\hline Extrato aquoso $0,1 \mathrm{mg} / \mathrm{mL}$ & $77,99 \pm 14,11$ & $1,86 \pm 0,21$ & $0,12 \pm 0,10$ & $2,3 \pm 0,13^{* * * a}$ \\
\hline Extrato aquoso $0,5 \mathrm{mg} / \mathrm{mL}$ & $92,81 \pm 3,31$ & $0,45 \pm 0,92^{* *_{a}}$ & $0,37 \pm 0,24^{\star \star a}$ & $0,74 \pm 0,52$ \\
\hline
\end{tabular}

${ }^{a}$ Diferença estatisticamente significativa em relação ao controle negativo ao nível de ${ }^{*} p<0,05 ;{ }^{* *} p<0,01$ e ${ }^{* * *} p<0,0001$ (Dunnett's Multiple Comparison Test).

aquoso das sementes de Amburana cearensis foi confirmada pela redução do edema de pata induzido pela carragenina, sendo tal efeito observado em até 24 horas após a administração do flogógeno. Trata-se de modelo experimental de inflamação aguda, em que a carragenina induz inflamação pela liberação de prostaglandinas, ocasionando a formação de edema e a migração leucocitária (Sousa et al., 2007). Destaca-se que na inflamação aguda duas fases são identificadas: a primeira, detectada em torno de uma hora, chamada de fase rápida, marcada pela liberação de histamina, serotonina e bradicinina; e a segunda, chamada de tardia (1-6 h), em que mediadores como as cininas e prostaglandinas são liberados após duas e três horas, respectivamente, as últimas resultando da ativação da ciclo-oxigenase 2 (COX-2) (Bispo et al., 2000; Silva et al.,2005). Considerando que qualquer substância que cause inibição ou redução da ação da carragenina é considerada como tendo ação antiinflamatória (Kummer \& Coelho, 2002), os resultados aqui encontrados demonstrando que o extrato aquoso da Amburana cearensis produziu redução do edema induzido pelo flogógeno a partir da segunda hora de administração, evidenciam que os constituintes ativos presentes nas sementes dessa espécie apresentam atividade antiinflamatória e que atuam na fase tardia da inflamação.

Como visto (Tabela 2), o aumento da liberação da medula óssea de neutrófilos imaturos (bastões) para o sangue ocorre quando aumenta a demanda funcional de neutrófilos para os tecidos ou em casos de leucemias mielógenas ou mielomonocíticas agudas ou crônicas. A presença de neutrófilos imaturos no sangue, acima do número normal para a espécie, constitui um desvio à esquerda. A hipersegmentação neutrofílica (2 a 4 lóbulos) é visto quando há uma maior permanência destes na circulação, caracterizado pela presença de grânulos citoplasmáticos lisossomais. Esta sobrevida intravascular prolongada caracteriza o desvio à direita. Os eosinófilos têm participação na regulação alérgica e resposta aguda inflamatória e pode induzir dano tecidual (eosinofilia). As principais funções dos eosinófilos são: fagocitose e atividade bactericida, atividade parasiticida, regulação das respostas alérgicas e inflamatórias e injúria tecidual (Thrall et al., 2007).

Antiinflamatórios não-esteróides, como o ácido acetilsalicílico (AAS), inibem a Ciclooxigenase, reduzindo a biossíntese de prostaglandinas, diminuindo o processo inflamatório. No presente estudo, o extrato aquoso testado apresentou ação semelhante àquela do AAS, utilizado como droga padrão, em duas e três horas após a administração da carragenina, sendo tal efeito mais duradouro do que aquele produzido pelo AAS, tal efeito poderia envolver a inibição da migração de neutrófilos e do aumento da permeabilidade vascular no foco inflamatório, ações justificadas pelos achados de redução do volume do exsudato e da migração leucocitária pelo extrato de Amburana cearensis.

No estudo fitoquímico realizado por Canuto \& Silveira (2007), Almeida et al. (2010) e Noldin et al.( 2006) um dos principais componentes químicos encontrados nas sementes de Amburana cearensis foi a cumarina, a qual juntamente com outras substâncias, é responsável pela atividade broncodilatadora, antiinflamatória, vasodilatadora, antitrombótica, espasmolítica, entre outros, validando cientificamente o extrato aquoso das sementes de Amburana cearensis através do uso popular como anti-inflamatório.

Estudos nas áreas de microbiologia e farmacologia são necessários para a caracterização da atividade in vitro e in vivo das plantas na busca da determinação da atividade antimicrobiana destes produtos naturais e o controle de qualidade fitopatológica das espécies e de seus produtos acabados (Foglio et al., 2006).

Neste estudo não foi evidenciada atividade antimicrobiana, contra as cepas de bactérias 
utilizadas uma vez que o extrato aquoso das sementes de Amburana cearensis não inibiu o crescimento bacteriano nas concentrações e metodologia empregada. É importante destacar que a atividade antimicrobiana pode estar relacionada não só com as características da planta estudada, como também pelo fato de que diferentes espécies apresentam diferentes princípios ativos, pelas características das cepas testadas e da metodologia analítica empregada (Catão, 2007; Santos et al., 2011).

Os testes de citotoxicidade/mutagenicidade realizados pelo sistema teste de Allium cepa baseiamse em diversos parâmetros de análise, como por exemplo, padrões nucleolares atípicos, os quais consistem em um grande número de células com pareamento heteromórfico de nucléolos. O aparecimento de micronúcleos é a conseqüência da quebra cromossômica, evidenciando claramente a manifestação de distúrbios do processo mitótico. No presente estudo o extrato apresentou potencial mutagênico em concentração de $0,5 \mathrm{mg} / \mathrm{mL}$. Agentes mutagênicos podem ser detectados, citologicamente pela inibição do ciclo celular, interrupção em metáfases, indução de alterações cromossômicas numéricas e estruturais e de trocas entre cromátides irmãs entre outros (Silva et al., 2009; Bagatini et al., 2007).

O conhecimento do potencial mutagênico desta espécie através da análise do ciclo celular de Allium cepa serve como indicativo de segurança para a população que utiliza o chá medicinal como única alternativa para o tratamento de doenças. Em virtude do uso difundido de Amburana cearensis para fins terapêuticos realização de estudos científicos que justificassem a sua indicação para afecções respiratórias.

\section{CONCLUSÃO}

O extrato aquoso das sementes de Amburana cearensis apresentou efeito antiedematogênico no modelo experimental utilizado e nas concentrações testadas, sugerindo potencial aplicação para fins terapêuticos. Entretanto, na avaliação microbiológica, o extrato aquoso não inibiu o crescimento de bactérias Gram positiva da cepa Sthapylococcus aureus e de Gram negativas das cepas Escherichia coli e Pseudomonas aeruginosas, o que evidencia a necessidade de realização de estudos adicionais para confirmação de ausência de ação antimicrobiana. O extrato apresentou ainda ação tóxica e mutagênica em células eucarióticas (Allium cepa) cultivadas, demonstrando a necessidade de estudos adicionais que demonstrem a segurança na utilização do extrato de Amburana cearensis.

\section{AGRADECIMENTOS}

Aos auxiliares e técnicos de laboratório da Faculdade NOVAFAPI Cleiton Catarino, Márcio Leonardo Nobre, Débora Cássia Gomes, Líbia, Zilene Abreu, Emília Abreu e D. Lúcia, pelo apoio durante o desenvolvimento dos experimentos.

\section{REFERÊNCIAS}

ALMEIDA, J. R. G. S. et al. Amburana cearensis - uma revisão química e farmacológica. Scientia Plena, v. 6, n. 11, 2010.

BAGATINI, M. D.; SILVA, A. C. F.; TEDESCO, S. B. Uso do sistema teste de Allium cepa como bioindicador de genotoxicidade de infusões de plantas medicinais. Rev. bras. farmacogn., v.17, n.3, João Pessoa, jul./ set., 2007.

BISPO et al. Avaliação da atividade antiedematogênica e antinociceptiva do extrato aquoso de Bumélia sartorium Mart. Biologia geral e experimental. São CristóvãoSE, p. 36-41, 2000.

BRITO, M. V. H. et al. Efeito dos óleos de andiroba e copaíba na miosite induzida em ratos. Revista Paraense de Medicina, v. 20, p. 17 - 23, Abril - Junho, 2006.

CANUTO, K. M; SILVEIRA, E R. Constituintes químicos da casca do caule de Amburana cearensis A.C. Smith. Fortaleza - CE, Quim. Nova, v. 29, n. 6, p. 1241, mar 2006.

CANUTO, K.M. Aspectos químicos do estudo interdisciplinar (Química - Agronomia Farmacologia) de Amburana cearensis A.C. Smith. Tese (Doutorado em Química Orgânica) - Universidade Federal do Ceará, Fortaleza - Ceará, 2007.

CANUTO, K. M. et al. Uso de Plantas Jovens de Amburana cearensis A. C. Smith: Alternativa para Preservação e Exploração Econômica da Espécie. Embrapa SemiÁrido, Petrolina - PE, p.15, abr. 2008.

CATÃO, R.M.R. Atividade antimicrobiana e efeitos biológicos de riparinas sobre bactérias e fungos leveduriformes. 126p. Tese (Doutorado - Área de Concentração em Farmacologia) - Departamento de Farmácia, Universidade Federal da Paraíba, João Pessoa, 2007.

CUNHA, M. C. L.; FERREIRA, R. A. Aspéctos morfológicos da semente e do desenvolvimento da planta jovem de Amburana cearensis (Arr. Cam.) A. C. Smith - Cumaru - Leguminosae Papilionoideae. Revista Brasileira de Sementes, v. 25, n. 2, p. $89-96,2003$.

FISKESJO, G. The Allium test as a standard in environmental monitoring. Hereditas, v.102, n.1, p.99112. 1985.

FOGLIO, M. A. et al. Plantas medicinais como fonte de recursos terapêuticos: Um modelo multidisciplinar. Multiciência, n. 7, Out. 2006.

JUNIOR, C. C.; SCHEFFER, M. C.; MING, L. C. Cultivo Agroecológico de Plantas Medicinais, Aromáticas e Condimentares. Curitiba, 2006.

KUMMER, C. L.; COELHO, T. C. R. B. Antiinflamatórios não esteróides inibidores da ciclooxigenase - 2 (COX - 2): Aspectos atuais. Rev. Bras Anestesiol, p. 498 - 
512, 2002.

LIMA, R. R. et al. Inflamação em doenças neurodegenerativas. Revista Paraense de Medicina, v.21, p. 29 -33, Abril - Junho, 2007.

MACIEL, M. A. M. et al.; Plantas Medicinais: A necessidade de estudos multidisciplinares. Química Nova, Rio de Janeiro, v.25, n.3, p.429 - 438, 2002.

MASSONE, F., Anestesiologia Veterinária Farmacologia e Técnicas, 4 ed., Rio de Janeiro: Guanabara Koogan, 2002.

MESSIAS, J. B. et al. Parâmetros hematológicos de Rattus norvegicus obtidos através de método automatizado e não - automatizado. Medicina Veterinária, Recife, v.3, n.2, p. 1-8, Abr-jun, 2009.

NOLDIN, V.F.; ISAIAS, D.B.; CECHINEL FILHO, V. Gênero Calophyllum: importância clínica e farmacológica. Química Nova, v.29, p.549-54, 2006.

PERON, A. P.; CANESIN, E. A.; CARDOSO, C. M. Potencial mutagênico das águas do Rio Pirapó (Apucarana, Paraná, Brasil) em células meristemáticas de raiz de Allium cepa L. Revista Brasileira de Biociência, Porto Alegre, v. 7, n. 2, p. 155-159, abr./jun. 2009.

ROSSI, T. Identificação de espécies florestais, Amburana cearensis (Freire Allemão).IPEF - Instituto de Pesquisas e Estudos Florestais. São Paulo, 2008.

SANTOS, V. L. et al.; Avaliação da atividade antimicrobiana de Maytenus rigida Mart. (Celastraceae). Rev. bras. plantas med., v.13, n.1, Botucatu, 2011.

SILVA et al.; Investigação do efeito analgésico central e antiinflamatório de Conocliniopsis prasiifolia (DC) R.M. King e H. Robinson em roedores. Acta Farm. Bonaerense, v. 24, n.4, p. 533-537, Abril, 2005.

SILVA et al.; Estudo da atividade mutagênica das plantas, Euphorbia milii Des Moulins e Ricinus communis $\mathrm{L}$ através do teste de Allium cepa. Rev. bras. farmacogn., vol.19, n.2, João Pessoa, abr./jun., 2009.

SILVA, N. C. C. Estudo comparativo da atividade antimicrobiana de extratos e óleos essenciais de plantas medicinais e sinergismo com drogas antimicrobianas. Dissertação (Mestrado em biologia geral e aplicada, área de concentração de biologia de parasitas e microorganismos (BPM) - Universidade Estadual Paulista “Julio Mesquita Filho"), Botucatu,São Paulo, 2010.

SOUSA et al. Efeitos farmacológicos e toxicológicos do extrato de Posoqueria acutifólia Mart. (Rubiaceae) em roedores. Rev. Cienc. Farm. Básica Apl., v. 28, n.1, p.51-56, Juiz de Fora - MG, 2007.

THRALL, M. A. et al. Hematologia e Bioquímica Clínica Veterinária. 1 Ed. São Paulo: Roca, 2007.

TOMAZZONI, M. I.; NEGRELLE, R. R. B.; CENTA, M .L. Fitoterapia popular: a busca instrumental enquanto prática terapêutica. Texto Contexto Enfermagem, Florianópolis, 2006. 